\title{
Global Woody Biomass Harvest Volumes and Forest Area Use Under Different SSP-RCP Scenarios
}

Pekka Lauri, Nicklas Forsell, Mykola Gusti, Anu Korosuo, Petr Havlík and Michael Obersteiner*

International Institute for Applied Systems Analysis (IIASA), Schlossplatz 1, A-2361 Laxenburg, Austria

\begin{abstract}
In this study, we investigate the effects of climate change mitigation and socioeconomic development on global forest resources use. The analysis is based on the Global Biosphere Management Model (GLOBIOM), which is a recursive dynamic land-use model. Climate change mitigation and socioeconomic development are included in the model as exogenous parameters taken from the SSP-RCP scenarios, which separate between the shared socioeconomic pathways("SSPs") and the representative concentration pathways ("RCPs"). The effect of SSP-RCP scenarios is restricted to factors that are quantitatively documented in the SSP database (economic growth, population growth, bioenergy demand, and carbon prices). Our results indicate that both climate change mitigation and socio-economic development may increase harvest volumes and harvested area considerably in the future. This happens because there are no opportunity costs of using forest area for harvesting in the model. We show that such opportunity costs can be added in the model by considering carbon storage changes between forest types and carbon payments on them. These payments increases woody biomass prices and make woody biomass harvesting for modern bioenergy less profitable mitigation option relative to carbon sequestration in the standing forests. However, the payments do not have much impact on the profitability of
\end{abstract}

*Correspondence author: Pekka Lauri, pekka.lauri@iiasa.ac.at. We thank two anonymous reviewers and the editor of the special issue (Brent Sohngen) whose comments helped to improve this paper considerably.

ISSN 1104-6899; DOI 10.1561/112.00000504

C)2019 P. Lauri, N. Forsell, M. Gusti, A. Korosuo, P. Havlík and M. Obersteiner

Supplementary material is available at:

http://dx.doi.org/10.1561/112.00000504_supp 
woody biomass harvesting for material products and traditional bioenergy. The reason is that energy crops provide a substitute for woody biomass use for modern bioenergy while there are less substitutes available for woody biomass use for material products and traditional bioenergy. Provided that carbon payments can be used as a policy instrument to control impacts of climate change mitigation on harvest volumes and harvested area, an unfavorable future socioeconomic development may cause a greater threat to the world's forests than climate change mitigation.

Keywords: SSP-RCP scenarios, Harvest volumes, Recursive dynamic land-use model, Carbon payments

\section{Introduction}

Humans have used woody biomass for millennia as raw material for construction, furniture and tools ("material production") and as fuelwood for heating and cooking ("traditional bioenergy"). In the last 50 years woody biomass use for material products has been increasing relatively constantly in all regions while woody biomass use for traditional bioenergy has been decreasing in the high income regions and increasing in the low income regions (FAO, 2018). The main driver behind this development has been socioeconomic development and this trend is expected to continue in the future (Raunikar et al., 2010). More recently woody biomass has also been used for industrial scale energy production ("modern bioenergy"). Woody biomass use for modern bioenergy is expected to increase in the future due to climate change mitigation, which causes additional pressure for forest resources use besides socioeconomic development.

The effects of climate change mitigation and socioeconomic development on global forest resources use can be analyzed using the SSP-RCP scenario framework (Van Vuuren et al., 2011; Riahi et al., 2017). SSP-RCP scenarios separate between the shared socioeconomic pathways ("SSPs") and the representative concentration pathways ("RCPs"). The RCPs describe projections for atmospheric concentration of greenhouse gases under different climate change mitigation policies. The SSPs describe different pathways of population and economic growth, income distribution, trade and consumption patterns. Related to forests, SSP-RCP scenarios have been used to analyze land-cover changes (Doelman et al., 2018), traditional bioenergy (Santos et al., 2017) and residues and energy crops use for modern bioenergy (Daioglou et al., 2019). However, these studies focus on land-cover changes or single feedstocks and consequently do not consider overall forest resources use. Recently Daigneault et al. (2019) have considered the impact of SSPs on forest resources use by 
developing Forest Sector Pathways (FSPs). However, FSPs are currently documented only qualitatively and there exists not yet any commonly agreed way to quantify them.

Increased pressure for forest resources use in the future has raised concern and produced conflicting statements about impacts on forest carbon storage and sustain ability (Schulze et al., 2012; Birdsey et al., 2018). A number of studies based on biophysical forest simulation models argue that harvesting causes a temporary carbon storage loss $(=$ carbon debt $)$, which can become permanent if the carbon debt is not paid back (Holtsmark, 2012; Agostini et al., 2014; Ter-Mikaelian et al., 2015; Bentsen, 2017). The payback time of carbon debt depends on the regrowth of harvested biomass and the development of the reference system. Infinite payback time occurs when forest carbon storage stabilizes permanently at a lower level. This happens typically when old-growth primary forests are converted into managed forests (Harmon et al., 1990). While carbon debt models predict that increased harvest volumes tend to decrease forest carbon storage, empirical evidence on the effects of increased harvest volumes is not clear. According to empirical literature the world's forest carbon stock has been increasing in the recent decades despite increasing harvest volumes (Pan et al., 2011), but it is unclear if this is caused by management or some other effect (Pan et al., 2013; Bellassen and Luyssaert, 2014; Grassi et al., 2018). On the regional level forest carbon stocks have been decreasing in some regions (tropical zone) (Baccini et al., 2017; Pearson et al., 2017) while increasing on other regions (boreal and temperate zones) (Kauppi et al., 2010; Pan et al., 2013). There is also some evidence that carbon stocks are lower in selective logging forests and secondary forests than in primary forests, but there is not much difference between carbon stocks in selective logging forests and secondary forests (Ferreira et al., 2014, 2018). Finally, Erb et al. (2018) has estimated that actual carbon stocks of forests are 25-38\% lower than potential carbon stocks of forests without human activities.

In addition to biophysical simulation models and empirical assessments, global forest resources use has been investigated by partial equilibrium forest sector models, which add economic incentives and market adjustments in the analysis (Latta et al., 2013). Raunikar et al. (2010) have studied the implications of increased modern bioenergy demand by using the Global Forest Products Model (Buongiorno et al., 2003). They concluded that increased harvest volumes tend to decrease forest carbon storage in most regions. On the other hand, Daigneault et al. (2012), Favero et al. (2017) and Kim et al. (2018) have studied the effects of increased modern bioenergy demand by using the Global Timber Model (Sohngen et al., 1999). They concluded that increased harvest volumes tends to increase forest carbon storage in most regions. The opposite results can be explained by different forest owner behavior assumptions in the models. In intertemporal optimization models, such as the Global Timber Model, forest owners anticipate harvest volume increases and start to adjust 
rotation times and management intensity before the increase occurs, which tends to increase forest carbon storage relatively to current level (Sohngen et al., 1999; Sedjo and Tian, 2016). In the recursive dynamic models, such as the Global Forest Products Model, forest owners do not anticipate harvest volume increases, which forces them to adjust rotation times and management intensity when the increase occurs. This tends to decrease forest carbon storage relatively to current level (Sohngen and Sedjo, 1998).

Finally, global forest resource use has been investigated by land-use models (Kraxner et al., 2013; Fricko et al., 2016; Doelman et al., 2018; Humpenöder et al., 2018; Daioglou et al., 2019). Land-use models are usually recursive dynamic models, which do not consider forest management explicitly based on changes in rotation times, stocking densities and other forest management activities. Instead, they consider land-use changes, which can happen between different land-cover types ("forest-cover change") or within the same land-cover type ("forest type change"). Forest types are usually based on the Global Forest Resources Assessment (FRA) national level data (FRA, 2015; Keenan et al., 2015; Chazdon et al., 2016) and different downscaling methods (Kindermann et al., 2008; Kraxner et al., 2017; Schulze et al., 2012).

Forest resources use and their impact on forest carbon storage can be controlled by carbon payments (taxes/subsidies) on forest carbon storage changes (Van Kooten et al., 1995; Sohngen and Mendelsohn, 2003). Recursive dynamic land-use models typically consider carbon storage changes between land-cover types, but not between different forest types (Havlik et al., 2011; Fricko et al., 2016; Doelman et al., 2018). This implies that there are no opportunity costs of using forest area for harvesting and carbon payments do not have direct impacts on harvest volumes. The main reasons for this simplification is missing global level data on carbon storage changes between forest types. Carbon storage changes between land-cover types can be measured relatively reliably by remote sensing data while measuring carbon storage changes between forest types requires forest inventory data, which is not generally available in the global scale especially for tropical regions (Pearson et al., 2017). Carbon storage changes between forest types have been estimated by different extrapolation methods based on the available remote sensing data and inventory data, but these estimates include many uncertainties (Baccini et al., 2017; Erb et al., 2018; Pugh et al., 2019).

Carbon payments on forest carbon storage changes have been studied in the recursive dynamic model by Lecocq et al. (2011), Buongiorno and Zhu (2013) and Nepal et al. (2013). They show that carbon payments give forest owners incentives to set aside forest land for carbon sequestration and consequently create opportunity costs of using forest area for harvesting. Buongiorno and $\mathrm{Zhu}$ (2013) show that carbon price $30 \$ / \mathrm{tCO}_{2}$ increases global industrial roundwood prices $94 \%$ and decreases global harvest volumes by $9 \%$ in 2030 . This indicates that industrial roundwood demand is relatively 
inelastic in respect to carbon payments as the payments increase industrial roundwood prices relatively more than harvest volumes. Lecocq et al. (2011) and Nepal et al. (2013) show that in the national level the effect of carbon payments might be less dramatic due to national budget constraints and leakage effects.

In this study, we investigate the effects of climate change mitigation and socioeconomic development on global forest resources use. In particularly, we study global woody biomass harvest volumes and forest area use under different SSP-RCP scenarios. The analysis is based on the Global Biosphere Management Model (GLOBIOM) (Havlik et al., 2011; 2014), which is a recursive dynamic land-use model and includes climate change mitigation and socioeconomic development as exogenous parameters taken from the SSP-RCP scenario database. In the SSP-RCP scenario calculations by the MESSAGEGLOBIOM model (Fricko et al., 2017), carbon payments were implemented only for land-cover changes and they do not have direct effects on harvest volumes. They have some indirect effects through avoided deforestation and increased afforestation, but these effects remain small, because afforested areas are excluded from production use and deforestation does not limit harvest volumes in most regions. The SSP-RCP scenario analysis is extended in this study to include carbon payments on forest type changes. We assume that the conversion of primary forests to managed forests is taxed and the restoration of managed and secondary forests is subsidized according to resulting biomass stock changes. These type of carbon payments create opportunity costs of using forest area for harvesting, and consequently have direct effects on harvest volumes. For simplicity, the carbon storage of harvested wood products and carbon payments on them are not considered, because they do not have any direct effects on land owners' decision making and harvest volumes.

The rest of the paper is organized as follows. In Section 2 we introduce the model and the methodology used in the analysis. Section 3 presents the results of the model. In section 4 we discuss the results of the model and provide conclusions. A formal description of the model is included in the supplementary material.

\section{Model}

The Global Biosphere Management Model (GLOBIOM) is a global spatially explicit agricultural and forest sector model, in which the world is divided into 30 economic regions and about 200000 land-use units (Havlik et al., 2011; 2014). The model is solved recursively using biophysical data from Global Forest Model (G4M) (Kindermann et al., 2006, 2008; Gusti and Kindermann, 2011) and Environmental Policy Integrated Climate Model (EPIC) (Williams, 1995). The biomass demand for modern bioenergy and carbon prices are based 
on the SSP-RCP scenario data (IIASA, 2018). In particular, we use the values of SSP-RCP scenario data that are calculated by the MESSAGE-GLOBIOM integrated assessment model (Fricko et al., 2017). The biomass demands for traditional bioenergy and material products are based on FAOSTAT data (FAO, 2018) and shifted over time by GDP and population growth as described in the SSP-RCP scenario data (IIASA, 2018). The forest sector representation includes forestry and forest industry modules. In this study, we use a version of the model that is similar to Lauri et al. (2017) except that the forestry module is extended to include five forest types and carbon payments on forest type changes. Moreover, the forest industry module is extended to include some new products (different paper grades, recycled paper, pellets).

\subsection{Forestry Module}

The forestry module defines forest-cover changes, forest type changes, allowable harvest volumes and development of biomass stocks. The forestry module includes five forest types (primary forests, secondary forests, restored forests, low intensity managed forests, and high intensity managed forests). Primary forests are forests where there are no clearly visible indications of human activities and the ecological processes are not significantly disturbed (FRA, 2015). The base year area of primary forests is based on FRA (2015) country level data on primary forests, which is downscaled to land-use unit level by the G4M. The remaining forests are divided to managed forests, which are regularly harvested, and secondary forests, which are abandoned managed forests. Managed and secondary forests are assumed to be degraded in the sense that they have lower biomass stock than primary forests and they do not recover by themselves back to primary forests. However, it is possible to recover them by restoration. The managed forest area is further divided to areas of low intensity selective logging and high intensity even-aged logging. The base-year areas of managed forests are based on FRA (2015) national level data on production forests and planted forests, which are downscaled to land-use unit level by GLOBIOM. Planted forest area is used as a minimum constraint for high intensity even-aged logging, that is, high intensity managed forest area is allowed to be higher than planted forest area if this is necessary to meet the base year demand. The base-year area of secondary forests is received as a residual term when primary and managed forests are removed from the total forest area. After the base year, the development of forest-cover and different types of forest areas is modelled endogenously and depends on the forest products demand, harvest costs, allowable harvest volumes per area, carbon prices, demand for agricultural land, land-use change costs and land-use change constraints.

Biophysical data for different forest types is generated by the G4M utilizing available biomass, land-cover and net primary productivity (NPP) data (Cramer et al., 1999; JRC, 2003; FRA, 2015). Biophysical data includes 
biomass growth rates, mortality, biomass stocks, and maximum allowable harvest volumes of different feedstocks for each land use unit. To handle forest age-class dynamics in the recursive optimization model, it is assumed that all forests are initially steady-state normal forests. Normal forests have a uniform distribution of age-classes and in each period the oldest age-class is removed by harvesting or mortality. This implies that allowable harvest volumes and biomass stocks stay constant in the normal forests.

Biomass stocks of different forest types are based on two biomass stock maps ("actual" and "potential") generated by G4M. For managed and secondary forests, we use the actual biomass stock map, where the biomass stocks are scaled to FRA (2015) aboveground and belowground biomass stocks. For primary, restored, and afforested forests, we use the potential biomass stock map, where the biomass stocks are scaled to Erb et al. (2018) potential aboveground and belowground biomass stocks without human activities. The changes of biomass stock can be caused by forest-cover or forest type changes. Because potential biomass stocks are higher than actual, primary forests conversion to managed forests decreases forest carbon storage, restoration increases forest carbon storage, and secondary forests conversion to managed forests and intensification of management have no effect on forest carbon storage. In case of deforestation the whole forest carbon storage is lost while afforestation recovers forest carbon storage to primary forest level.

The transition between different forest types is modeled by assuming a temporary deviation from the initial normal-forest steady state until the new normal-forest steady state with different biomass stock is achieved. When a land area is afforested or managed/secondary forest is restored, then biomass growth exceeds removals and biomass stock increases until the potential maximum biomass stock is achieved. Afforested and restored forests biomass stock is assumed to increase by decreasing rate based on Chapman-Richards growth curves parametrized for three climate regions ("boreal", "temperate" and "tropical") (Humpenöder et al., 2014). When a primary forest is converted to the managed forest, then removals exceed biomass growth and biomass stock decreases until the managed forest steady-state biomass stock is achieved.

Harvested biomass from managed forests is divided into the following feedstocks categories: Industrial roundwood (=IW), logging residues $(=\mathrm{LR})$, and fuelwood $(=\mathrm{FW})$. The harvested area is largely determined by IW harvesting, which is stemwood that can be used for sawlogs and pulplogs. LR are woody biomass that is felled during the IW harvesting process, but not used for IW (i.e., harvest losses, branches and stumps). LR can be left in the forest or they can be removed and used for modern bioenergy like heat and power production. FW is excess stemwood or other parts of trees, which are collected by households for traditional bioenergy. FW harvesting does not directly compete with IW and LR harvesting, because FW harvesting is based much on residues that are not used for IW or LR. To be consistent FAOSTAT data, 
the harvest volumes of IW, FW, and LR are measured as volumes under bark (i.e., without bark).

\subsection{Forest Industry Module}

The forest industry module defines how harvested biomass is converted to forest sector products and bioenergy. The module includes five types of products: primary products, intermediate products, final products, by-products and recycled products. Primary products (IW, FW, and LR) come directly from the forests and their supply is based on the forestry model described above. Primary products are transformed into intermediate products (chemical pulp, mechanical pulp, and pellets) and final products (sawnwood, plywood, fiberboard, newsprint, printing \& writing paper, packaging materials, other papers, modern bioenergy, and traditional bioenergy) by using different production technologies. Besides final products the production technologies produce also by-products (sawdust, woodchips, bark, and black liquor), which can used to substitute for primary products in the production of final products. Recycled products (recycled paper and recycled wood) are intermediate products that are produced from final products through recycling after their use.

Demand for final products (except for modern bioenergy) is based on constant elasticity demand functions, which are parametrized by reference volumes and prices from FAOSTAT data (FAO, 2018) and shifted over time by GDP and population growth:

$$
\begin{array}{ll}
D_{t}\left(x_{t}\right)=\bar{x}_{t}\left(\frac{p_{t}}{\bar{p}}\right)^{\alpha} \quad \alpha \leq 0 \\
\bar{x}_{(t+1)}=\bar{x}_{t}\left(\frac{\operatorname{pop}_{(t+1)}}{p o p_{t}}\right)\left(\frac{g d p_{(t+1)}}{g d p_{t}}\right)^{\beta_{t}} \quad \beta_{t}>0
\end{array}
$$

where $x_{t}=$ quantity of demand in period $t, \bar{x}_{i}=$ reference quantity of demand in period $t, p_{t}=$ price in period $t, \bar{p}=$ reference price, $\operatorname{pop}_{t}=$ population in period $t, g d p_{t}=$ per capita gross domestic product (GDP) in period $t$, $\alpha=$ price elasticity and $\beta_{t}=$ income elasticity in period $t$.

Income and price elasticities for forest sector final products and traditional bioenergy are based on historical estimates, similar to Buongiorno et al. (2003). Price elasticities vary in the range from -0.1 to -0.6 depending on the product category and income level, which indicates that demands for forest sector final products and traditional bioenergy are inelastic and there are few substitutes for them in the short run. Different income elasticities are used for countries with low, medium and high GDP per capita. Typically the income elasticities are lower for high income regions, which implies a decreasing rate of demand increase over time. Income elasticities are positive for all final products except for newsprint and printing \& writing papers and 
traditional bioenergy. Newsprint and printing \& writing papers are assumed have negative income elasticities, because information technology development provides substitutes for them in the long run (Latta et al., 2016). Traditional bioenergy is assumed to have negative income elasticity to be consistent with the decreasing residential sector biomass use for energy in the SSP-RCP scenarios (IIASA, 2018).

Demand for modern bioenergy is based on SSP-RCP scenario data (IIASA, 2018). The modern bioenergy demand is derived from total bioenergy demand by subtracting the traditional bioenergy and other biomass (waste, agricultural residues) from total bioenergy. The amount of other biomass is estimated to be 31 EJ in 2010 and is kept constant over time (Lauri et al., 2017). Modern bioenergy can be produced from woody biomass or energy crops, which are assumed to be perfect substitutes in modern bioenergy production. Energy crops are woody or non-woody biomass that is grown in dedicated energy crops plantations, which are not included in the forest area (Lauri et al., 2017). Volumes of woody biomass and energy crops are converted to energy units using factor $1 \mathrm{GJ}=7.2 \mathrm{~m}^{3}$ (Lauri et al., 2014).

\subsection{SSP-RCP Scenarios}

In the SSP-RCP scenario framework socioeconomic development and climate change mitigation are separated to Shared Socioeconomic Pathways ("SSPs") and Representative Concentration Pathways ("RCPs"). A detailed description of these scenarios can be found in Van Vuuren et al. (2011) and Riahi et al. (2017). In this study we consider five socioeconomic development scenarios (SSP1-SSP5) and two RCP scenarios (RCPref and RCP2.6). ${ }^{1} \mathrm{SSP} 1$ is "sustainability scenario" with strict environmental boundaries. SSP2 is the "middle of the road" scenario with intermediate socio-economic development. SSP3 is "fragmentation scenario" with increased national rivalry. SSP4 is "inequality scenario" with polarized development between low and high income regions. SSP5 is "fossil fuels scenario" with continued exploitation of fossil fuels resources. RCPref is a non-mitigation (zero carbon price) scenario leading to a $3.8^{\circ} \mathrm{C}$ temperature increase in 2100 compared to the pre-industrial level. $\mathrm{RCP} 2.6$ is a high mitigation scenario leading to a $1.8^{\circ} \mathrm{C}$ temperature increase in 2100 compared to the pre-industrial level.

SSP-RCP scenario data is taken from the SSP-database, which is publicly available through IIASA (2018). The relevant variables for our study are

\footnotetext{
${ }^{1}$ Scenario RCP1.9 is not included, because it is infeasible for SSP3, SSP4, and SSP5. Scenario SSP3 RCP2.6 is replaced by SSP3 RCP3.4, which is the highest feasible mitigation scenario for SSP3. Intermediate RCP scenarios (RCP6.0, RCP4.5, and RCP3.4) are not included, because bioenergy demand and carbon prices increase parallel in the RCP scenarios. This means basically that intermediate RCP scenario results can be interpolated from RCPref and $\mathrm{RCP} 2.6$ results.
} 

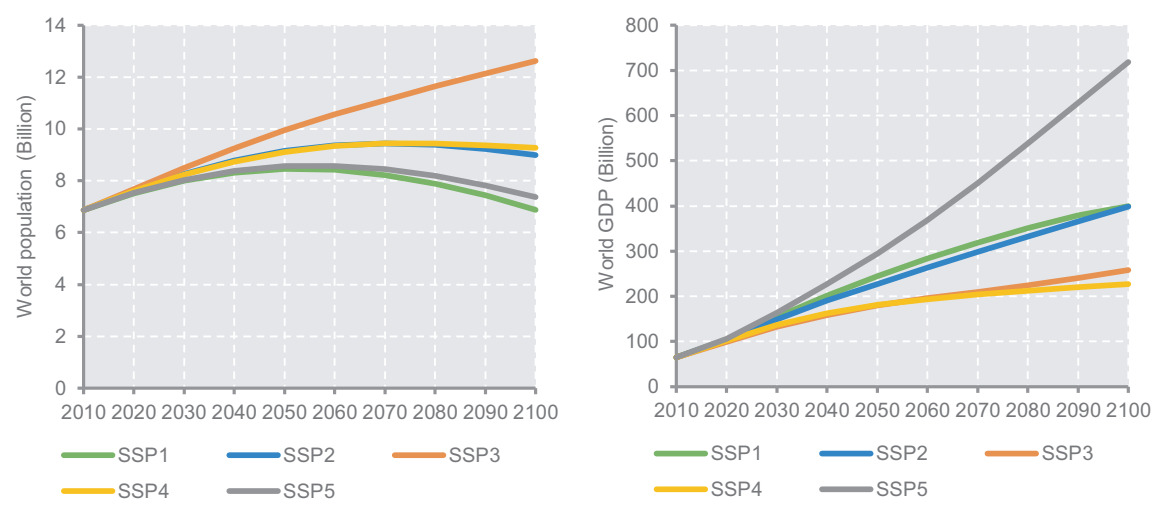

Figure 1: Population and GDP in different SSP scenarios (Source: IIASA, 2018).

economic growth, population growth, bioenergy demand and carbon prices. Economic and population growth develop in opposite directions in different SSP scenarios (see Figure 1). SSP1 and SSP5 have the highest GDP growth and the lowest population growth while SSP3 and SSP4 have the lowest GDP growth and the highest population growth. In SSP2 GDP and population growth fall in between the other scenarios, depicting continuation of historical trend.

Carbon prices and bioenergy demands vary across the SSP-RCP scenarios (Figure 2). In the scenario database, each SSP is calculated by a different IAM model. In addition, some SSPs are calculated by several IAM models. This complicates the interpretation of bioenergy demands and carbon prices between different SSPs, because the differences in bioenergy demand between the models can be larger than between the SSPs. In this study, we use bioenergy demands and carbon prices that are calculated by the MESSAGE-GLOBIOM model (SSP1, SSP2, and SSP3). For the scenarios SSP4 and SSP5 these bioenergy demands and carbon prices area not available, so we use the SSP2 bioenergy demands and carbon prices.

In the non-mitigation scenario (RCPref) carbon prices are zero for all SSPs while in the high mitigation scenario (RCP2.6) they increase over time with a SSP specific growth rate. The fragmentation scenario (SSP3) has the highest carbon price while the sustainability scenario ( $\mathrm{SSP} 1$ ) has the lowest carbon price. Bioenergy demand is higher in the high mitigation scenario RCP2.6 than in the non-mitigation scenario RCPref, because in the high mitigation scenario fossil fuel emissions are offset by negative emissions from bioenergy connected to carbon capture and storage (BECCS) (Van Vuuren et al., 2017). Bioenergy demand also varies across SSP scenarios due to different socioeconomic energy consumption patterns (Riahi et al., 2017). The bioenergy demand is the 

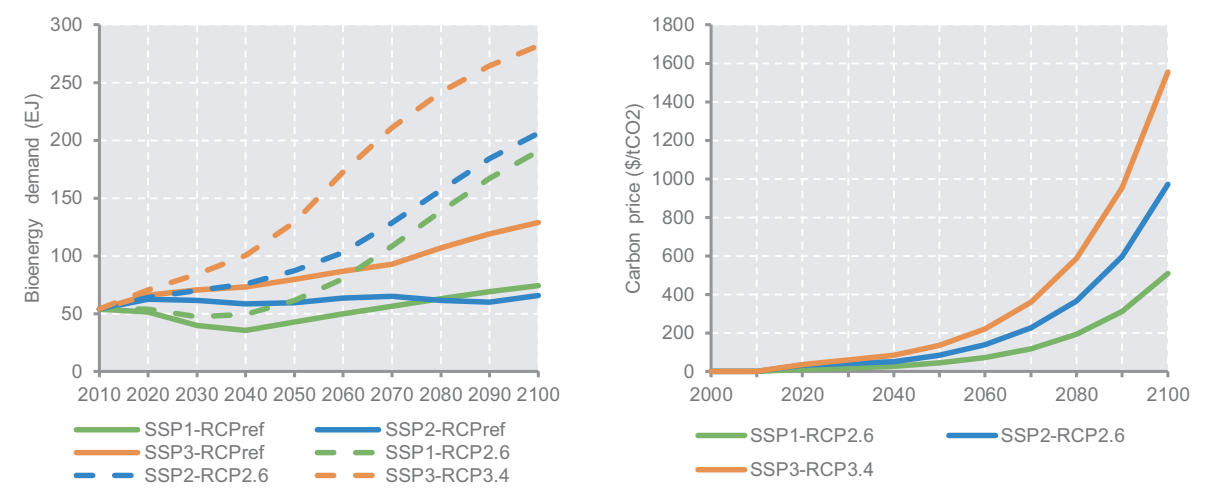

Figure 2: Bioenergy demand and carbon prices in SSP-RCP scenarios calculated by MESSAGE-GLOBIOM model (Source: IIASA, 2018).

highest in the fragmentation scenario SSP3 and the lowest in the sustainability scenario SSP1.

\subsection{Carbon Payments on Biomass Stock Changes}

Carbon payments are applied to marginal biomass stock changes, that is, carbon payments are a function of the biomass stock change in that period. In the recursive dynamic model landowners consider only current period payments, which implies that future biomass stock changes and carbon payments do not affect their current choices. The length of the period in the GLOBIOM model is 10 years, which implies that landowners' planning horizon is 10 years.

Carbon payments depend on carbon prices and biomass stock changes

$$
\begin{aligned}
T_{t}^{\text {carbon }} & =p_{t}^{\text {carbon }}\left(B m_{t}-B m_{t-1}\right) \\
B m_{t} & =B m_{t-1}+\lambda_{t} B m_{t}-H_{t}
\end{aligned}
$$

where $T_{t}^{\text {carbon }}=$ carbon subsidy in period $t$ (if negative then carbon tax), $p_{t}^{\text {carbon }}=$ carbon price in period $t, B m_{t}=$ carbon storage of living biomass in period $t, \lambda_{t}=$ growth rate of biomass in period $t$ (net of mortality) and $H_{t}=$ biomass harvest in period $t$.

If forest area is deforested then all biomass is harvested and $T_{t}^{\text {carbon }}=$ $-p_{t}^{\text {carbon }} B m_{t-1}<0$. If land area is afforested or forest area restored then there is no harvesting and $T_{t}^{\text {carbon }}=p_{t}^{\text {carbon }} \lambda_{t} B m_{t}>0$ as long as $\lambda_{t}>0$, that is, until the potential maximum steady state biomass stock is achieved. If primary forest area is converted to managed forests then harvest volumes exceed biomass growth and $T_{t}^{\text {carbon }}=p_{t}^{\text {carbon }}\left(\lambda_{t} B m_{t}-H_{t}\right)<0$ until the managed forest steady state biomass stock is achieved. In the managed forest steady state $\lambda_{t} B m_{t}=H_{t}$ and $T_{t}^{\text {carbon }}=0$. 


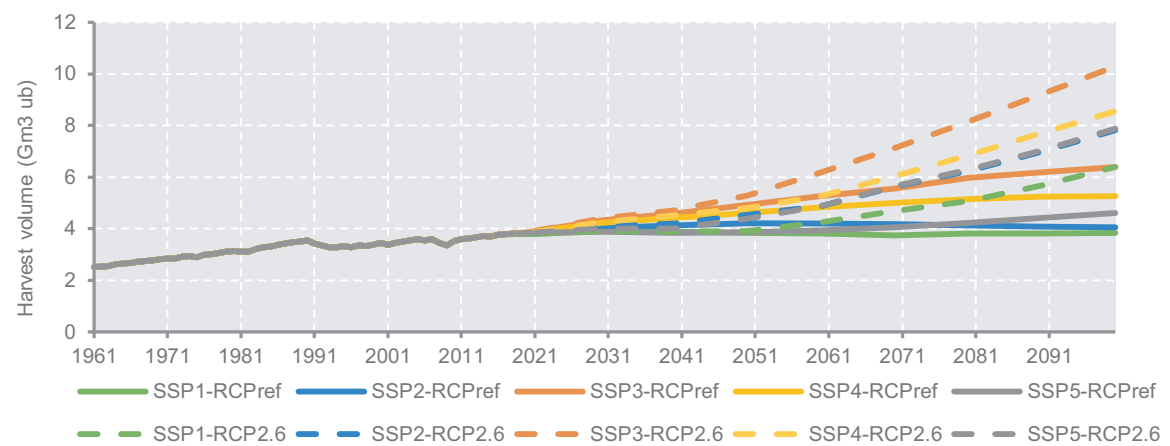

Figure 3: Historical and future woody biomass harvest volumes. Historical volumes are based on FAOSTAT data (FAO, 2018) and future volumes are outcome of GLOBIOM model.

\section{Results}

\subsection{Historical and Future Harvest Volumes}

Global woody biomass harvest volume has increased by $50 \%$ between 1961 and 2017, from 2517 to $3777 \mathrm{Mm}^{3}$ (Figure 3). The main driver behind this is considered to be socio-economic development (Buongiorno et al., 2003). According to our projections, the global woody biomass harvest volume will rise during $2017-2100$ by $14 \%-272 \%$ depending on the SSP-RCP scenario. Compared to the relatively steady historical levels, the range of possible future harvest volumes is wide and creates significant uncertainty about the future development of the global forest sector and the consequences to the world's forests.

Future harvest volumes depend both on socioeconomic development and climate change mitigation. Socioeconomic development alone without climate change mitigation (RCPref scenario) increases harvest volumes by $14 \%-69 \%$ between 2017 and 2100 , from 3777 to $3829-6391 \mathrm{Mm}^{3}$. The lowest increase happens in the sustainability scenario SSP1, while the highest increase is seen in the fragmentation scenario SSP3. Socioeconomic development combined with climate change mitigation (RCP2.6 scenario) increases harvest volumes by $69 \%-272 \%$ between 2017 and 2100 , from 3777 to $6392-10290 \mathrm{Mm}^{3}$. Similarly to RCPref scenario the lowest increase happens in the sustainability scenario SSP1 and the highest in the fragmentation scenario SSP3.

\subsection{Harvest Volumes in Different SSP-RCP Scenarios}

The harvested woody biomass can be divided to industrial roundwood harvesting for material products (IW material), industrial roundwood harvesting for modern bioenergy (IW energy), fuelwood harvesting for traditional bioenergy 
(FW) and logging residues harvesting for modern bioenergy (LR). The future development of IW material depends mainly on GDP growth, because in the SSP scenarios GDP increases relatively more than population over time (Figure 1). Climate change mitigation affects IW material only indirectly through by-product and competition effects (Lauri et al., 2017), which is relatively small compared the effect of socioeconomic development (see Figure 4).

The future development of $\mathrm{FW}$ depends mainly on population growth. There are three reasons for this. First, traditional bioenergy has a negative income elasticity, which implies that population growth has a higher effect on FW than GDP growth. Second, traditional bioenergy demand is assumed to have a separate demand function, which does not depend on total bioenergy demand, and consequently on climate change mitigation. Third, FW harvesting does not directly compete with IW and LR harvesting, because FW harvesting is based much on residues that are not used for IW or LR.

The future development of LR and IW energy depend son socioeconomic development as well as on climate change mitigation. Climate change mitigation increases LR and IW energy in all SSP scenarios. The increase is the highest in the fragmentation scenario SSP3 and lowest in the sustainability scenario SSP1, following the bioenergy demand development in these scenarios (see Figure 2). LR are a by-product of IW harvesting, which makes LR a cheaper energy source than IW. For this reason LR are used for energy in the non-mitigation scenario RCPref while IW use for energy arises only in the high mitigation scenario RCP2.6.

The future development of total harvest volumes is a combination of these four effects. In the non- mitigation scenario RCPref, the total harvest volume development is determined largely by fuelwood harvesting, which increases the total harvest volume in SSP3 and SSP4 more than in SSP1, SSP2, and SSP5. In the high mitigation scenario RCP2.6, modern bioenergy demand increases industrial roundwood and logging residues harvesting compared to the non-mitigation scenario, which increases the variation between different SSP scenarios.

Carbon payments on forest type changes ("C-payments") decrease total harvest volumes considerably in the high mitigation scenario RCP2.6, but do not impact much the variation of harvest volumes driven by socioeconomic development. To understand this issue we need to look the effect of carbon payments on different feedstocks. C-payments increase woody biomass prices (Figure 5), which decreases the competitiveness of woody biomass in modern bioenergy markets but not in material product markets and traditional bioenergy use. There are three reasons for this. First, in the modern bioenergy markets LR and IW energy can be relatively easily replaced by energy crops. Second, there are few substitute feedstocks for IW in material use and FW in traditional bioenergy. Third, the demand for material products and traditional bioenergy is inelastic, that is, there are few substitute final products for them. 

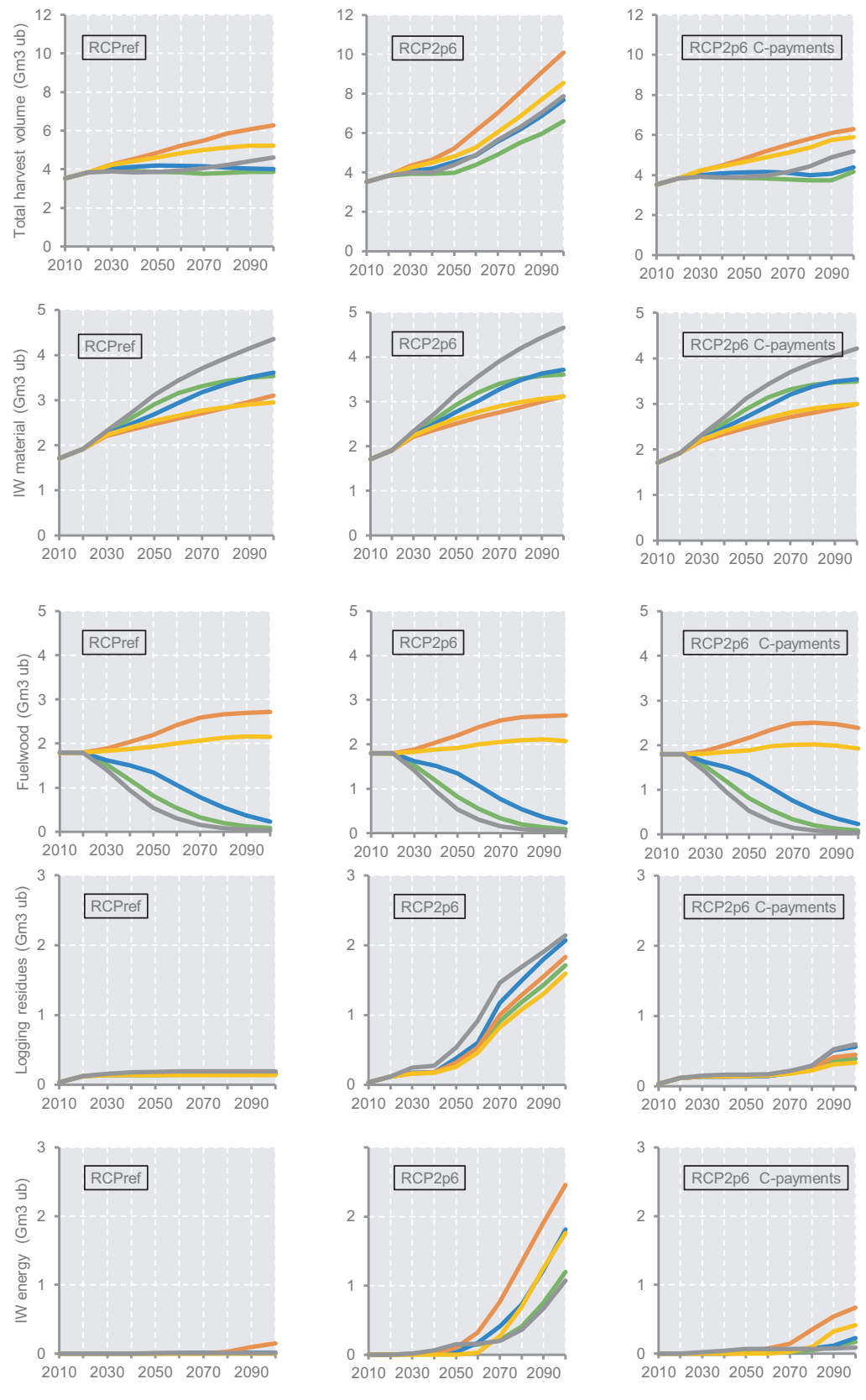

Figure 4: Woody biomass harvest volumes in different SSP-RCP scenarios divided to different feedstocks. 

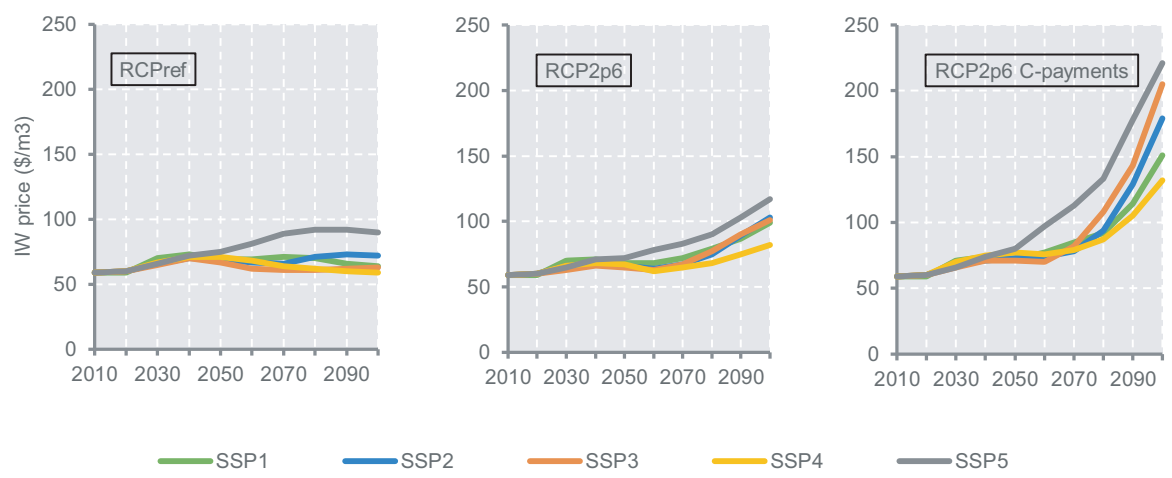

Figure 5: IW prices in different SSP-RCP scenarios.

\subsection{Forest Area Use in Different SSP-RCP Scenarios}

In the base year $(=2000)$ the model is calibrated to match FRA (2015) forest area data so that the total forest area is $4056 \mathrm{Mha}$, the primary forest area is 1299 Mha, the secondary forest area is 1576 Mha and the managed forest area is 1182 Mha. The managed forest area is allocated by the model further to low intensity selective logging forests composed of $680 \mathrm{Mha}$, and high intensity even-aged logging forests, composed of 502 Mha.

In the SSP2-RCPref scenario managed forest area increases by 249 Mha and in the SSP2-RCP2p6 scenario by 666 Mha by 2100 (Figure 6). This causes a decrease in primary and secondary forest area. However, part of this decrease is compensated by lower deforestation in the RCP2p6 scenario (221 Mha instead of $588 \mathrm{Mha}$ ). In the RCP2p6 C-payments scenario managed forest area increases by $378 \mathrm{Mha}$, which is about $45 \%$ less than without C-payments.

Managed forest areas (even-aged + selective logging) in different SSP-RCP scenarios are comparable to harvest volumes (Figure 7). Managed forest area increases most in the SSP5 scenario while harvest volumes in the SSP3 scenario (Figure 4). The reason for this is high GDP growth in the SSP5 scenario, which increases IW material and consequently harvested area. In the SSP3 scenario the increase of harvest volumes is caused high population growth and bioenergy demand, which increases FW and LR and consequently has less effect on harvested forest area.

C-payments decrease primary forest loss and leads to restoration of managed and secondary forests (Figure 8). Avoided primary forest loss due to C-payments is $160-390$ Mha while avoided deforestation is $300-387$ Mha, depending on the SSP scenario. Restored forest area varies from 689 to 933 Mha, while afforested areas ranges from 717 to 1093 Mhaacross the SSP scenarios. Consequently, the effect of carbon payments on forest type changes is compa- 


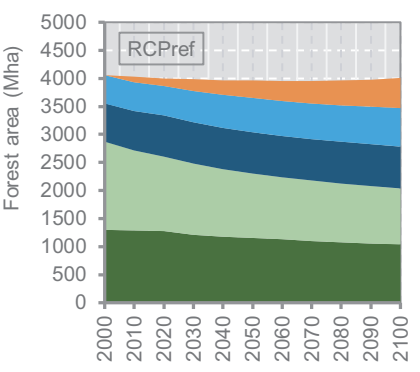

- Primary forests

- Low intensity selective logging

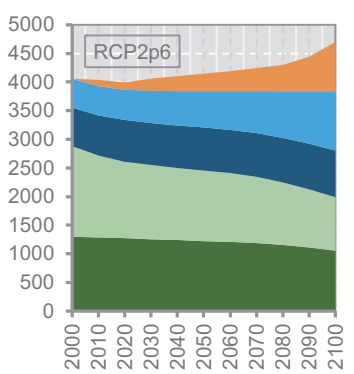

- Secondary forests

- High intensity even-aged logging

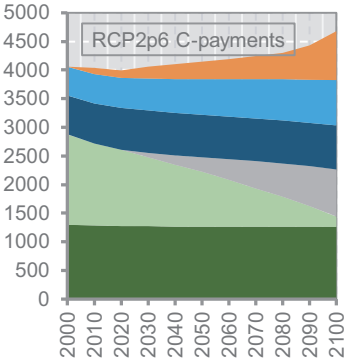

nestored forests

- Afforestation

Figure 6: Effect of C-payments on forest area types in the SSP2 scenario.
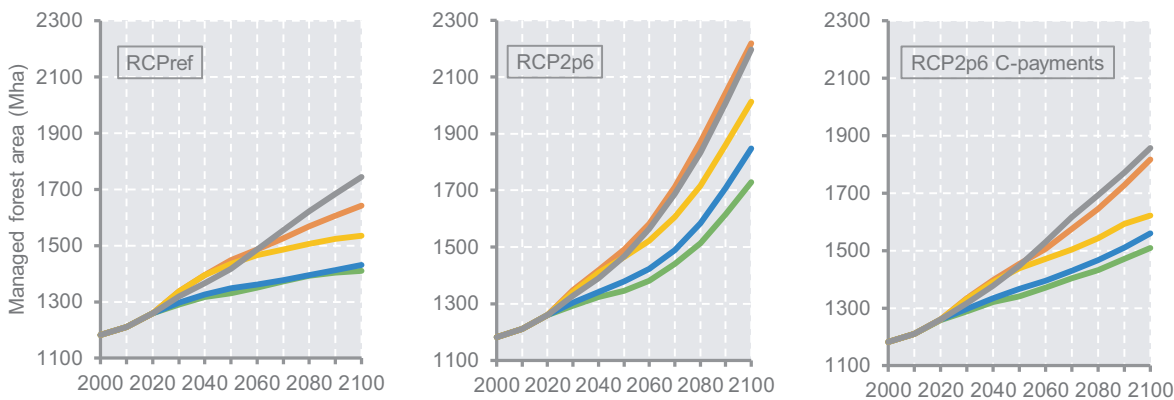

SSP1
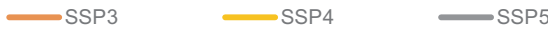

Figure 7: Managed forest area in different SSP-RCP scenarios.

rable to the effect of carbon payments on forest-cover changes if measured in terms of forest area changes. ${ }^{2}$

\subsection{Comparison of SSP-RCP Scenarios Effects}

The effects of climate change mitigation and socioeconomic development on global forest resources use can be assessed by comparing the range of harvest volume and harvested area differences in 2100 . The RCP range is calculated as a difference between the no mitigation and high mitigation scenarios for each

\footnotetext{
${ }^{2}$ Forest areas of the study may differ from the MESSAGE-GLOBIOM model forest areas reported in the SSP database (IIASA, 2018), because forest areas in the SSP database are calculated by G4M instead of GLOBIOM and they include some additional SSP specific assumptions on deforestation and afforestation besides economic and population growth, bioenergy demand, and carbon prices.
} 

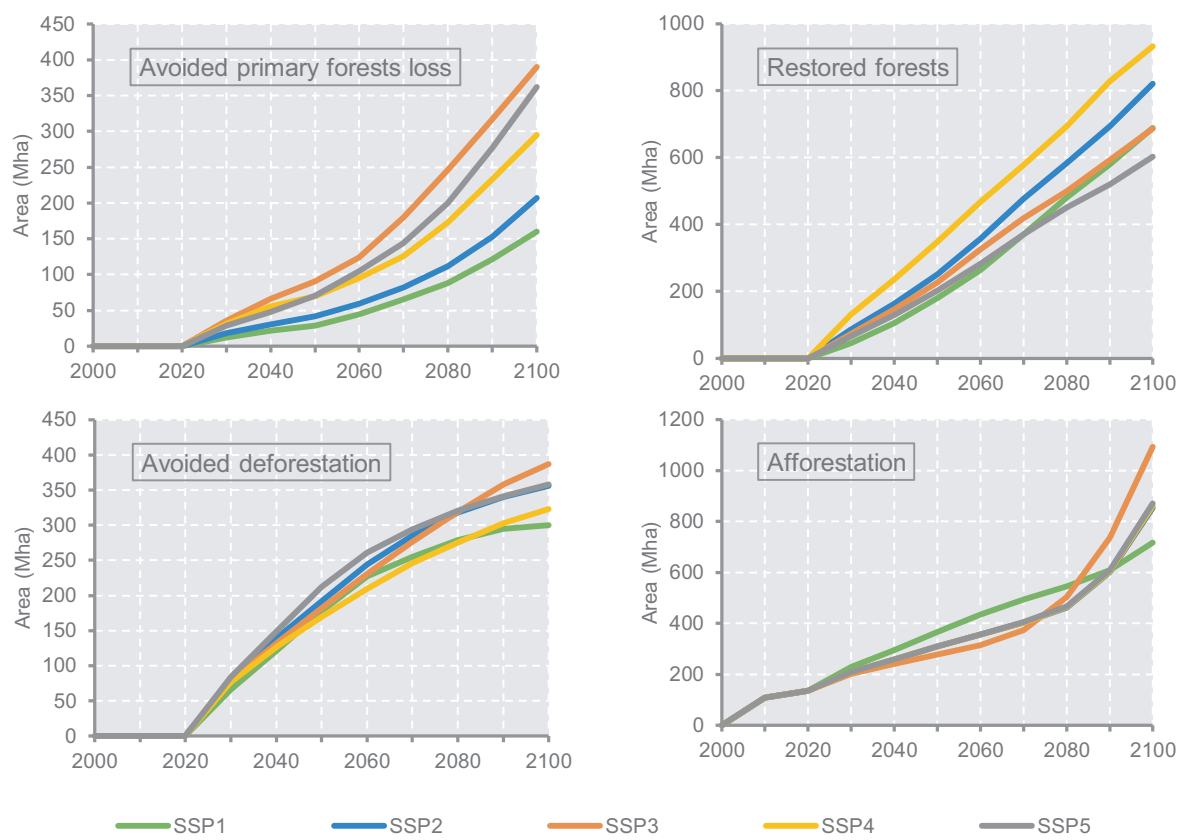

Figure 8: Avoided primary forests loss, avoided deforestation, restored forests and afforestation in RCP2p6 scenario with C-payments.

SSP. The SSP range is calculated as a difference between the SSP1 and other SSPs for each RCP. The sustainability scenario SSP1 is used as a reference to calculate the SSP range, because it has the lowest harvest volume and harvested area, and we do not have "no socioeconomic development" scenario for a reference.

Both climate change mitigation and socio-economic development may increase harvest volumes considerably in the future (Figure 9). In 2100 the $\mathrm{RCP}$ range is 2563 to $3899 \mathrm{Mm}^{3}$ and the $\mathrm{SSP}$ range is 217 to $3898 \mathrm{Mm}^{3}$. The biggest difference in total harvest volumes, 2562 to $3898 \mathrm{Mm}^{3}$, arises between the sustainability scenario SSP1 and the fragmentation scenario SSP3. These means that moving from sustainable development to fragmented development would increase total harvest volume by $2562 \mathrm{Mm}^{3}$ in the non-mitigation scenario RCPref and by $3898 \mathrm{Mm}^{3}$ in the high mitigation scenario RCP2.6.

$\mathrm{C}$-payments considerably decrease the effect of climate change mitigation on the future harvest volumes but have a smaller impact upon the effect of socio-economic development. In 2100 the range of harvest volumes across the RCPs without C-payments is 2563 to $3899 \mathrm{Mm}^{3}$, and with C-payments it is 226 to $629 \mathrm{Mm}^{3}$. The range of harvest volumes across SSPs without C-payments is 217 to $3898 \mathrm{Mm}^{3}$ and with C-payments 541 to $2814 \mathrm{Mm}^{3}$. 


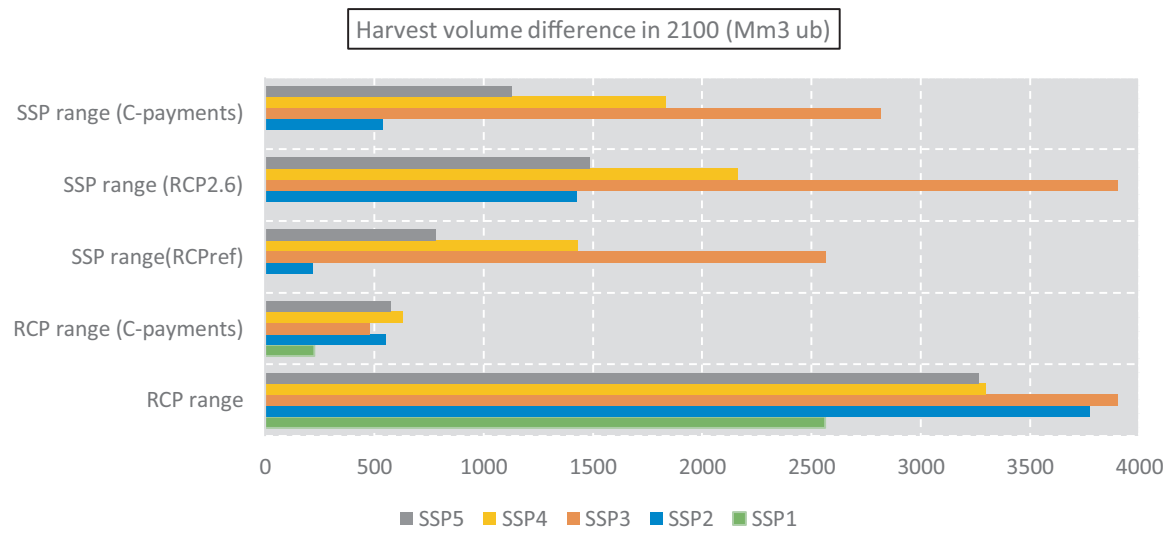

Figure 9: Harvest volume differences in 2100.

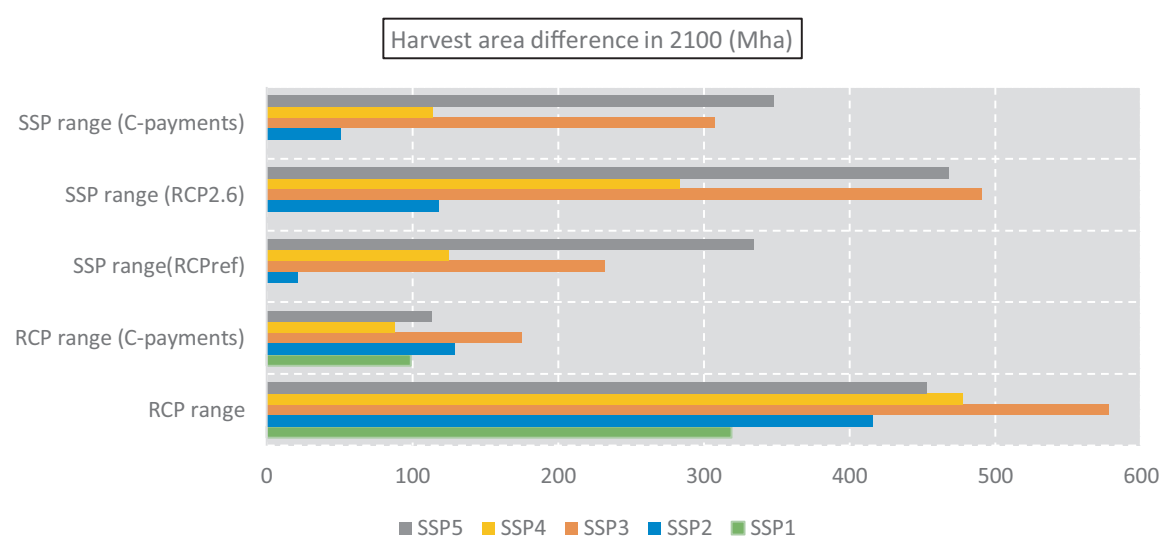

Figure 10: Harvested area differences in 2100.

The effect of SSP-RCP scenarios on harvested area is comparable to the effect on harvest volumes (Figure 10). The main difference is that the effect of socioeconomic development is relatively higher in the SSP5 scenario if the effect is measured by harvested area instead of harvest volumes. The reason for this is high IW material use in the SSP5 scenario, which increases harvested area. The difference between the sustainability scenario SSP1 and the fragmentation scenario SSP3 is 334-468 Mha. This result means that moving from sustainable development to fragmented development would increase total harvest volume by 334 Mha in the non-mitigation scenario RCPref and by 468 Mha in the high mitigation scenario RCP2.6. It is notable that the increase of harvested area is lower than the increase of harvest volumes if they are compared 
to total harvested area and harvest volume. In particular, moving from sustainable development to fragmented socio-economic development would increase harvest volumes in 2100 by around $60 \%$ and harvested area by around $30 \%$. Consequently, the effect of climate change mitigation and socioeconomic development on global forest resources use is higher if measured in harvest volumes than if measured in harvested area changes.

\section{Discussion and Conclusions}

Woody biomass use for modern bioenergy is expected to increase in the future due to climate change mitigation, which has raised concern about the resulting impacts on forest carbon storage and sustainability. Much less attention has been paid to socioeconomic development, which has been a main driver of harvest volumes increase in the history. In this study, we have shown by using the SSP-RCP scenario framework and a recursive dynamic land-use model that both climate change mitigation and socio-economic development may increase harvest volumes and harvested area considerably in the future. Therefore, we should be equally concerned about the effects of socioeconomic development than about the effects of climate change mitigation on the world's forests. Our results indicate the range of possible future harvest volumes in different SSPs is wide compared to the relatively steady historical levels. This causes a considerable uncertainty about the future development of forest sector and the consequences to the world's forests. The biggest difference was found between the sustainability scenario SSP1 and the fragmentation scenario SSP3: moving from sustainable development to fragmented socio-economic development would increase harvest volumes in 2100 by $60 \%$ and harvested area by $30 \%$.

Carbon payments for forest carbon storage can be used as a policy instrument to control impacts of increased forest resources use on forest carbon storage and sustainability. Recursive dynamic land-use models do not usually consider carbon storage changes between forest types and consequently do not allow this option. This makes woody-biomass harvesting a relatively cheap mitigation option in these models, because using forests for harvesting has no opportunity costs. In this study, we have shown that it is possible to create such opportunity costs in the recursive dynamic land-use models by adding carbon payments on forest type changes. These payments increase woody biomass prices and decrease profitability of harvesting relative to carbon sequestration in the standing forests. In particular, the payments limit woody biomass harvesting if harvesting is sufficiently elastic relative to the payments. It was found that the payments decrease the impact of climate change mitigation on harvest volumes, but they do not have much of an effect on the impact of socioeconomic development. The reason for this is that woody biomass 
harvesting for modern bioenergy can be relatively easily replaced by energy crops while woody biomass harvesting for material products and traditional bioenergy is more difficult to replace and the demand for forest sector material products and traditional bioenergy is inelastic. Thus it is more difficult to control harvest volumes increase due to socioeconomic development than due to climate change mitigation.

The effect of carbon payments can be measured also in terms of forest area changes. It was found that carbon payments on forest type changes increases primary forest area about the same amount than carbon payments decreases deforestation. Moreover, such payments lead to restoration of secondary forests, which results in afforestation in the high mitigation scenario RCP2p6. This means that forest-type changes are comparable to forest-cover changes if measured in terms of forest area. In terms of carbon sequestration the mitigation potential of forest-type changes is smaller than mitigation potential of forest-cover changes, because forest-type changes remove/add some share of forest biomass while forest-cover changes affect the whole forest biomass. To compare carbon sequestration potentials of forest-cover and forest type changes properly would require that the GLOBIOM model would be extended to include initial age-class distribution of forests instead of the normal forest distribution. On possible source of such data could be the new Global Forest Age Database (GFAD) (Pugh et al., 2019).

Extending a recursive dynamic land-use model to include carbon payments on forest type changes is not a trivial modelling exercise and includes some strong simplifications. First, carbon payments are applied to marginal biomass stock changes, which is economically correct way to analyze them in the intertemporal model (Van Kooten et al., 1995; Sohngen and Mendelsohn, 2003). In the recursive dynamic model this approach might lead suboptimal biomass stocks and harvest volumes in comparison to intertemporal optimization, because landowners do not take account future biomass stock changes and payments. An alternative way to include carbon payments in the recursive dynamic model would be to use annualized carbon payments based on the expected future steady state biomass stocks. Annualized carbon payments could be interpret as a rental value of holding carbon in atmosphere (tax) or in land (subsidy). However, this approach would require that carbon prices stay constant over time, which is not true for the SSP-RCP scenarios. Second, we use potential biomass stocks for primary, restored and afforested forests, and actual biomass stocks for managed and secondary forests. It is unclear if potential biomass stocks should be used for primary forests, because there is not sufficiently inventory data available on primary forests in the global level (Baccini et al., 2017; Erb et al., 2018; Pugh et al., 2019). Moreover, it is unclear if managed and secondary forests can be fully recovered back to primary forests (Ferreira et al., 2014; Chazdon and Guariguata, 2016; Berenguer et al., 2018; Bernal et al., 2018). Finally, primary forests may not achieve their potential 
biomass stocks, because they are exposed to natural disturbances (Kauppi et al., 2018). Third, the division of forest area to different forest types rely on FRA (2015) data on forest characteristics and functions, which is based on member country reporting instead of some systematic and independent measurement system (Keenan et al., 2015; Chazdon et al., 2016; Schulze et al., 2019).

The advantage of recursive dynamic land-use models is that they are able to handle high resolution biophysical data such as biomass, land-cover and net primary productivity (NPP) maps. The limitation of recursive dynamic land-use models is that forest owners do not anticipate future socioeconomic development and climate change mitigation changes, but adapt to them when the change occurs. This type of behavior is suboptimal from perspective of intertemporal optimization, because it would be better to adapt rotation times and management intensities in advance, before the change occurs (Sohngen and Sedjo, 1998; Sedjo and Tian, 2016). It is unclear how much forest owners actually anticipate the future harvest volume changes and mitigation policies, because they may be myopic, credit constrained, or they may not be willing to make long-term commitments to store carbon in their forests. Even though forest owners would not anticipate the future, intertemporal optimization perspective is relevant for the policy analysis while it defines the optimal forest management response to the future harvest volume changes and mitigation policies. Policy makers can use the optimal response as a forest policy target and correct forest owners' incentives so that the optimal response is achieved. This type of analysis would require a combination of recursive dynamic landuse and intertemporal optimization models and remains an interesting subject of the future study.

\section{References}

Agostini, A., J. Giuntoli, and A. Boulamanti. 2014. "Carbon accounting of forest bioenergy, JRC Scientific and Policy Reports 25354, Joint Research Centre of the European Commission".

Baccini, A., L. Walker W. Carvalho, M. Farina, D. Sulla-Menashe, and R. A. Houghton. 2017. "Tropical forests are a net carbon source based on aboveground measurements of gain and loss". Science. 358(6360): 230-234.

Bellassen, V. and S. Luyssaert. 2014. "Managing forests in uncertain times". Nature. 506: 153-155.

Bentsen, N. 2017. "Carbon debt and payback time -lost in the forest?" Renewable and Sustainable Energy Reviews. 73: 1211-1217.

Berenguer, E., T. A. Gardner, J. Ferreira, L. E. O. C. Aragão, R. M. Nally, J. R. Thomson, I. C. G. Vieira, and J. Barlow. 2018. "Seeing the woods through the saplings: Using wood density to assess the recovery of human-modified Amazonian forests". Journal or Ecology. 106: 2190-2203. 
Bernal, B., L. Murray, and T. Pearson. 2018. "Global carbon dioxide removal rates from forest landscape restoration activities". Carbon Balance Management. 13(22): 1-13.

Birdsey, R., P. Duffy, C. Smyth, W. A. Kurz, A. J. Dugan, and R. Houghton. 2018. "Climate, economic, and environmental impacts of producing wood for bioenergy". Environmental Research Letters. 13: 1-9.

Buongiorno, J. and S. Zhu. 2013. "Consequences of carbon offset payments for the global forest sector". Journal of Forest Economics. 19: 384-401.

Buongiorno, J., S. Zhu, D. Zhang, J. Turner, and D. Tomberlin. 2003. The Global Forest Products Model. Elsevier.

Chazdon, R. L., P. Brancalion, L. Laestadius, A. Bennett-Curry, K. Buckingham, C. Kumar, J. Moll-Rocek, I. C. G. Vieira, and S. J. Wilson. 2016. "When is a forest a forest? Forest concepts and definitions in the era of forest and landscape restoration". Ambio. 45: 538-550.

Chazdon, R. and M. Guariguata. 2016. "Natural regeneration as a tool for largescale forest restoration in the tropics: prospects and challenges". Biotropica. 48(6): 716-730.

Cramer, W., D. Kicklighter, A. Bondeau, and et al. 1999. "Comparing global models of terrestrial net primary productivity (NPP): overview and key results". Global Science Biology. 5: 1-15.

Daigneault, A., B. Sohngen, and R. Sedjo. 2012. "Economic approach to assess the forest carbon implications of biomass energy". Environmental Science 83 Technology. 46(11): 5664-5671.

Daigneault, A., C. Johnston, A. Korosuo, J. S. Baker, N. Forsell, J. P. Prestemon, and R. C. Abt. 2019. "Developing Detailed Shared Socioeconomic Pathway (SSP) Narratives for the Global Forest Sector". Journal of Forest Economics. 34(1-2): 7-45.

Daioglou, V., J. Doelman, B. Wicke, and et al. 2019. "Integrated assessment of biomass supply and demand in climate change mitigation scenarios". Global Environmental Change. 54: 88-101.

Doelman, J., E. Stehfest, A. Tabeau, and et al. 2018. "Exploring SSP landuse dynamics using the IMAGE model: regional and gridded scenarios of land-use change and land-based climate change mitigation". Global Environmental Change. 48: 119-135.

Erb, K., T. Kastner, C. Plutzar, and et al. 2018. "Unexpectedly large impact of forest management and grazing on global vegetation biomass". Nature. 553: 73-76.

FAO. 2018. "FAOSTAT database". URL: www.fao.org/faostat.

Favero, A., R. Mendelson, and B. Sohngen. 2017. "Using forests for climate mitigation: sequester carbon or produce woody biomass?" Climate Change. 144(2): 195-206. 
Ferreira, J., T. A. Gardner, L. E. O. C. Aragão, P. B. De Camargo, C. E. Cerri, M. Durigan, R. C. De Oliveira Junior, I. C. G. Vieira, and J. Barlow. 2014. "A large-scale field assessment of carbon stocks in human-modified tropical forests". Global Change Biology. 20: 3713-3726.

FRA. 2015. "Global Forest Resources Assessment". Main Report, FAO.

Fricko, O., P. Havlik, J. Rogelj, and et al. 2017. "The marker quantification of the Shared Socioeconomic Pathway 2: A middle of the road scenario for the $21^{\text {st }}$ century". Global Environmental Change. 42: 251-267.

Grassi, G., J. House, W. Kurz, and et al. 2018. "Reconciling global-model estimates and country reporting of anthropogenic forest $\mathrm{CO}_{2}$ sinks". Nature Climate Change. 8: 914-920.

Gusti, M. and G. Kindermann. 2011. "An approach to modeling land-use change and forest management on a global scale". In: SIMULTECH-2011. Proceedings of 1st International Conference on Simulation and Modeling Methodologies, Technologies and Applications. Noordwijkerhout. 180-185.

Harmon, M., W. Ferrell, and J. Franklin. 1990. "Effects on carbon storage of conversion of old-growth forests to young forests". Science. 247(4943): 699-702.

Havlik, P., U. Schneider, E. Schmid, and et al. 2011. "Global land-use implications of first and second generation biofuels targets". Energy Policy. 39: 5690-5702.

Havlik, P., H. Valin, M. Herrero, and et al. 2014. "Climate change mitigation through livestock system transition". Proceedings of the National Academy of Science. 111: 3709-3714.

Holtsmark, B. 2012. "Harvesting in boreal forests and the biofuel carbon debt". Climate Change. 112: 415-428.

Humpenöder, F., A. Popp, B. Bodirsky, and et al. 2018. "Large-scale bioenergy production: how to resolve sustainability trade-offs?" Environmental Research Letters. 13: 1-15.

Humpenöder, F., A. Popp, J. Dietrich, and et al. 2014. "Investigating afforestation and bioenergy CCS as climate change mitigation strategies". Environmental Research Letters. 9: 1-13.

IIASA. 2018. "SSP database". URL: https://tntcat.iiasa.ac.at/SspDb.

JRC. 2003. "Global land cover map for the year 2000 (GLC) database, European Commission Joint Research Centre". URL: https://forobs.jrc.ec.europa.eu/ products/glc2000/glc2000.php.

Kauppi, P., M. Hanewinkel, T. Lundmark, and et al. 2018. "Climate Smart Forestry in Europe, European Forest Institute".

Kauppi, P., A. Rautiainen, K. Korhonen, and et al. 2010. "Changing stock of biomass carbon in a boreal forest over 93 years". Forest Ecology and Management. 259: 1239-1244. 
Keenan, R., G. Reams, F. Achard, and et al. 2015. "Dynamics of global forest area: Results from the FAO Global Forest Resources Assessment 2015". Forest Ecology and Management. 352: 9-20.

Kindermann, G., I. McCallum, S. Fritz, and M. Obersteiner. 2008. "A global forest growing stock, biomass and carbon map based on FAO statistics". Silva Fennica. 42: 387-396.

Kindermann, G., M. Obersteiner, E. Rametsteiner, and I. McCallum. 2006. "Predicting the deforestation-trend under different carbon-prices". Carbon Balance and Management. 1: 1-17.

Kraxner, F., E. Nordstrom, P. Havlik, and et al. 2013. "Global bioenergy scenarios - Future forest development, land-use implications, and tradeoffs". Biomass and Bioenergy. 57: 86-96.

Kraxner, F., D. Schepaschenko, S. Fuss, and et al. 2017. "Mapping certified forests for sustainable management - A global tool for information improvement through participatory and collaborative mapping". Forest Policy and Economics. 83: 10-18.

Latta, G., A. Plantinga, and M. Sloggy. 2016. "The effects of internet use on global demand for paper products". Journal of Forestry. 114(4): 433-440.

Latta, G., H. Sjolie, and B. Solberg. 2013. "A review of recent developments and applications of partial equilibrium models of the forest sector". Journal of Forest Economics. 19: 350-360.

Lauri, P., N. Forsell, A. Korosuo, P. Havlik, and M. Obersteiner. 2017. "Impact of the $2^{\circ} \mathrm{C}$ target on the global woody biomass use". Forest Policy and Economics Energy Policy. 38: 121-130.

Lauri, P., P. Havlik, G. Kindermann, and et al. 2014. "Woody biomass energy potential in 2050". Energy Policy. 66: 19-31.

Lecocq, F., S. Caurla, P. Delacote, and et al. 2011. "Paying for forest carbon or stimulating fuelwood demand? Insights from the French Forest Sector Model". Journal of Forest Economics. 17: 157-168.

Nepal, P., P. Ince, K. Skog, and S. Chang. 2013. "Forest carbon benefits, costs and leakage effects of carbon reserve scenarios in the United States". Journal of Forest Economics. 19: 286-306.

Pan, Y., R. Birdsey, J. Fang, and et al. 2011. "A large and persistent carbon sink in the world's forests". Science. 333: 988-993.

Pan, Y., R. Birdsey, O. Phillips, and et al. 2013. "The structure, distribution, and biomass of the world's forests, Annual Review of Ecology". Evolution, and Systematics. 44: 593-622.

Pearson, T., M. L. Brown S, and et al. 2017. "Greenhouse gas emissions from tropical forest degradation: an underestimated source". Carbon Balance and Management. 12: 1-11.

Pugh, T., M. Lindeskog, B. Smith, and et al. 2019. "Role of forest regrowth in global carbon sink dynamics". PNAS. 116(10): 4382-4387. 
Raunikar, R., J. Buongiorno, J. Turner, and S. Zhu. 2010. "Global outlook for wood and forests with the bioenergy demand implied by scenarios of the Intergovernmental Panel on Climate Change". Forest Policy and Economics. 12: $48-56$.

Riahi, K., D. van Vuuren, E. Kriegler, and et al. 2017. "The shared socioeconomic pathways and their energy, land use, and greenhouse gas emissions implications: An overview". Global Environmental Change. 42: 153-168.

Santos, M., S. Dekker, V. Daioglou, and et al. 2017. "Modeling the effects of future growing demand for charcoal in the tropics". Frontiers in Environmental Science. 5: 1-12.

Schulze, E., C. Körner, B. Law, and et al. 2012. "Large-scale bioenergy from additional harvest of forest biomass is neither sustainable nor greenhouse gas neutral". Global Change Biology Bioenergy. 4(6): 611-616.

Schulze, K., Z. Malek, and P. Verburg. 2019. "Towards better mapping of forest management patterns: A global allocation approach". Forest Ecology and Management. 432: 776-785.

Sedjo, R. and X. Tian. 2016. "Does wood bioenergy increase carbon stocks in forests?" Journal of Forestry. 110: 304-311.

Sohngen, B. and R. Mendelsohn. 2003. "An optimal control model of forest carbon sequestration". American Journal of Agricultural Economics. 81: $1-13$.

Sohngen, B., R. Mendelsohn, and R. Sedjo. 1999. "Forest management, conservation, and global timber markets". American Journal of Agricultural Economics. 85(2): 448-457.

Sohngen, B. and R. Sedjo. 1998. "A comparison of timber market models: static simulation and optimal control approaches". Forest Science. 44: 24-36.

Ter-Mikaelian, M., S. Colombo, and J. Chen. 2015. "The burning question: does forest bioenergy reduce carbon emissions? A review of common misconceptions about forest carbon accounting". Journal of Forestry. 113: $57-68$.

Van Kooten, C., C. Binkley, and G. Delcourt. 1995. "Effect of carbon taxes and subsidies on optimal forest rotation age and supply of carbon services". American Journal of Agricultural Economics. 77: 365-74.

Van Vuuren, D., A. Edmonds, A. Kainuma, and et al. 2011. "The representative concentration pathways: an overview". Climate Change. 109: 5-31.

Van Vuuren, D., A. Hof, A. Mariesse, and et al. 2017. "Open discussion of negative emissions is urgently needed". Nature Energy.

Williams, J. 1995. "The Epic model". In: Water Resources Publications. Ed. by V. Singh. 909-1000. 